\title{
LA LECCIÓN VERTIGINOSA. PABLO DE LA TORRIENTE BRAU EN LA GUERRA CIVIL ESPAÑOLA
}

\author{
THE VERTIGINOUS LESSON. PABLO DE LA TORRIENTE \\ BRAU IN THE SPANISH CIVIL WAR
}

\section{JESÚS CANO REYES*}

\section{RESUMEN}

Pablo de la Torriente Brau es una figura emblemática entre los corresponsales hispanoamericanos de la Guerra Civil Española. En este artículo se reconstruye el recorrido que lleva al periodista cubano por el país en guerra y en pocas semanas lo convierte en combatiente de la República que encuentra la muerte en diciembre de 1936. A partir del examen de las crónicas que escribe desde España, se analizan los diversos desplazamientos del escritor: el desplazamiento físico desde el extranjero al epicentro de la guerra y el desplazamiento del corresponsal al miliciano; por otro lado, el análisis de su epistolario pone de manifiesto otros aspectos de la escritura distintos a los de los escritos periodísticos. Por último, se subraya la conversión de Pablo de la Torriente Brau en un mito tras su temprana muerte, que además de suscitar una enorme cantidad de homenajes y actos en su memoria, origina una constelación de crónicas, elegías, poemas y toda suerte de textos diversos.

Palabras clave: Pablo de la Torriente Brau, Guerra Civil Española, Cuba, corresponsal, crónicas.

\section{ABSTRACT}

Pablo de la Torriente Brau is an emblematic figure among the Latin-American correspondents during the Spanish Civil War. This paper restores the journey that leads the Cuban writer and journalist around the country at war turning him, in a few weeks, into a Republican combatant who meets his death in December 1936. Based on the examination of the chronicles he wrote from Spain, various shifts in the nature and

* Doctor Europeo en Literatura Hispanoamericana, Universidad Complutense de Madrid, España. Correo electrónico: jesuscanoreyes@ucm.es 
style of the writer are analysed: physical shift from abroad to the epicentre of war, and shift from correspondent to conscript. Additionally, the analysis of his collected letters show other aspects of writing that differ from his journalistic texts. Lastly, this essay highlights the conversion of Pablo de la Torriente Brau into a myth after his early death that, apart from generating a large number of tributes in his memory, gave origin to a stream of chronicles, elegies, poems, and all sort of texts from varied authors.

Keywords: Pablo de la Torriente Brau, Spanish Civil War, Cuba, correspondent, chronicles.

Recibido: 04.10.17. Aceptado: 05.12.17.

Para Amado del Pino, in memoriam

\section{"ME VOY A ESPAÑA"}

$\mathrm{E}$

L 6 DE AGOSTO DE 1936, días después de que se había desencadenado la Guerra Civil Española, Pablo de la Torriente Brau (San Juan de Puerto Rico, 1901 - Majadahonda, España, 1936) escribe desde su exilio neoyorquino una carta, posiblemente dirigida a su amigo Juan Marinello, donde expresa con tanto enardecimiento su idea de viajar a España que esas líneas pueden convertirse en el símbolo de una llamada que buena parte de los intelectuales hispanoamericanos no puede desoír:

He tenido una idea maravillosa: me voy a España, a la revolución española. Allá en Cuba se dice, por el canto popular jubiloso: "No te mueras sin ir a España". Y yo me voy a España ahora, a la revolución española, en donde palpitan hoy las angustias del mundo entero de los oprimidos. La idea hizo explosión en mi cerebro, y desde entonces está incendiando el gran bosque de mi imaginación. [...] Pero ahora yo me voy a España, a ser arrastrado por el gran río de la revolución. A ver un pueblo en lucha. A conocer héroes. A oír el trueno del cañón y sentir el viento de la metralla. A contemplar incendios y fusilamientos. A estar junto al gran remolino silencioso de la muerte... (2005, pp. 14-15).

Además de la pasión con la que se entrega Pablo de la Torriente a la causa española, como puede apreciarse en estas palabras, otros elementos contribuyen a la mitificación del corresponsal: su carácter pionero (es uno de los primeros latinoamericanos en viajar a España tras el levantamiento armado); el abundante repertorio de textos -crónicas y cartas- que afortunadamente han podido conservarse, otorgando un considerable relieve 
y una gran humanidad a su figura; $y$, por último, su trepidante historia personal, condensada en pocos meses y bruscamente interrumpida cuando la muerte lo alcanza en España, con las armas en la mano, en diciembre de 1936, hecho que lo eleva de inmediato a la categoría de mártir.

Pablo de la Torriente parte de Nueva York rumbo a Europa en el vapor Île de France el 1 de septiembre de 1936 (Z. Torriente Brau, 2006, p. 29; Bello, 2003, p. 186; Casaus, 2007, p. 243). Tras pasar por Bruselas y por París, llega por fin a tierra española. Por los apuntes de sus cuadernos inéditos ${ }^{1}$, se sabe que ya está en Barcelona al menos el día 18 de septiembre. Su aspiración es llegar rápidamente a Madrid, lo que logra finalmente el día 24 (Torriente Brau, 2005, p. 37).

Deseoso de aproximarse a la línea de fuego, el 2 de octubre se marcha a la sierra de Guadarrama con la columna de Paco Galán, y allí permanece ocho días en estrecha convivencia con los soldados. En Buitrago de Lozoya protagoniza uno de los episodios más significativos de su experiencia en España: la polémica con el enemigo en La Peña del Alemán, un combate verbal de trinchera a trinchera con un "cura fascista" en el que pone en práctica el arma que mejor maneja: la elocuencia.

Antes y después, Torriente Brau vive en Madrid la fiebre y el vértigo de la inminente defensa de la ciudad, pronuncia un discurso por radio, entrevista a personalidades de la República, analiza la posición de las distintas fuerzas políticas, escucha las explosiones cercanas de la artillería y asiste a la multitudinaria proyección de la película Los marinos de Kronstadt. En los momentos de calma, se relaciona con intelectuales como Ramón Menéndez Pidal y, sobre todo, José María Chacón y Calvo, que el 2 de octubre anota en su diario: "Es una fuerza de la naturaleza. Me separan de él muchas cosas: me atraen su cordialidad, su bondad nativa, su sentido del deber" (p. 80); unos días después, cuando el periodista regresa de Buitrago, se hace eco de la batalla dialéctica que este ha de contarle en detalle y

\footnotetext{
${ }^{1}$ Víctor Casaus, como director del Centro Pablo, tiene en su poder las libretas que rellenó Torriente Brau con sus apuntes durante su paso por España: "Se trata de cuatro libretas de taquigrafía en las que el corresponsal anotó datos e impresiones desde el 19 de septiembre hasta el 11 de noviembre de 1936" (2005, p. XII). El mismo corresponsal las menciona en su carta del 21 de octubre: "Tengo varias libretas llenas de impresiones, de notas, de opiniones" (p. 47). Algunas de estas anotaciones -muy pocas-son transcritas en el citado prólogo.
} 


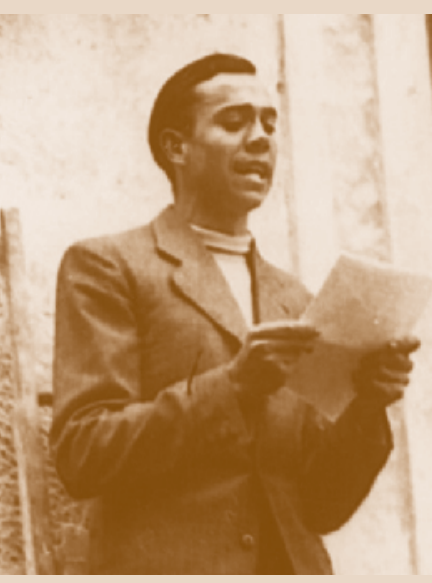

M. Hernández concluye: "Sigue Pablo con su entusiasmo y su ardimiento de toda la vida" (2009, p. 93).

Entretanto, a la par que se zambulle en el torbellino de la guerra, Torriente Brau escribe sin tregua, incesantemente, tanto cartas cromo crónicas periodísticas. Ya el 15 de noviembre (lo explica él mismo en una de sus cartas, después de un silencio de once días), se ha producido una transformación: el periodista se ha convertido en comisario político del batallón de Valentín González, el Campesino; según el atinado juego de palabras de Jorge Ferrer, "el corresponsal que iba a 'dar parte' de la guerra se ha convertido él mismo en parte de la guerra" (2011, p. 16). El desplazamiento es trascendental: el testigo ha dado un paso al frente y ha pasado a integrar una historia de la que hasta el momento ha sido un mero espectador. Como ha anunciado unos meses atrás en su carta de despedida desde Nueva York, el periodista ha sido arrastrado por el gran río de la revolución (un río que, lo sabemos ahora, desembocará para él en la muerte un mes después). En su epístola del 15 de noviembre busca justificar su decisión, que "acaso sea un error desde el punto de vista periodístico" pero "comprenderás que en estos momentos había que abandonar toda posición que no fuera la más estrictamente revolucionaria de acuerdo con la angustia y las necesidades del momento" (p. 84).

A partir de entonces, la guerra lo arrastra con el ímpetu de una corriente vertiginosa. Siempre próximo al Campesino, es destinado a Alcalá de Henares. Entregado a la urgencia y la dedicación exclusiva de la guerra, apenas siente deseos de conocer la ciudad y visitar la casa cervantina (carta del 21 de noviembre); unos días después (carta del 28) comprueba, decepcionado, que de "Cervantes no hay sino una estatua, obra maestra de ridiculez, y una placa con faltas de ortografía, en el lugar donde estuvo su casa” (p. 111). Con Campesino recorre los pueblos de los alrededores y realiza labores de reclutamiento. También, incluso, oficia matrimonios revolucionarios, "que terminan en una comida con discursos revolucionarios. El Campesino firma y yo leo las actas y todo el mundo tan contento" (p. 120). Por otra parte, es en Alcalá donde conoce a Miguel Hernández, que también es comisario en el mismo batallón: "Descubrí un poeta en el batallón, Miguel Hernández, un muchacho considerado como uno de los mejores poetas españoles, que estaba en el cuerpo de zapadores. Lo nombré jefe del Departamento de Cultura, y estuvimos trabajando en los planes para publicar el periódico de la brigada y la creación de uno o dos periódicos murales" (p. 110). En muy poco tiempo establecen una relación estrecha: el día 2 de diciembre, a fin de reclutar efectivos, ambos realizan una incursión a Mejorada del 
Campo, donde el pueblo los recibe en armas y los encañona en repetidas ocasiones durante la refriega hasta que llega Campesino y logra apaciguar la situación.

No obstante, su batalla definitiva tiene lugar en Majadahonda en las postrimerías de diciembre. Allí, el día 19, Pablo de la Torriente cae combatiendo con las fuerzas republicanas. El cadáver queda varios días tendido en tierra enemiga hasta que logra ser rescatado.

\section{CRÓNICAS DEL PERIODISTA EN EL PARAPETO}

El libro Peleando con los milicianos (1938) incluye en su edición príncipe mexicana un total de quince crónicas, repertorio casi definitivo que apenas se ha visto incrementado o modificado en los años posteriores ${ }^{2}$. Por otro lado, hay que considerar que bajo el marbete de la crónica se ampara una notable variedad de textos, que oscilan entre el mayor o menor peso de la narración y la opinión, o el retrato de algún personaje individual o colectivo.

Un aspecto de extraordinario interés que se desprende de la lectura de las crónicas entendidas en su totalidad, no como meros textos independientes sino como piezas de un artefacto mayor -el libro o historia del periodista en su viaje hacia y a través de la guerra-, es lo que podríamos llamar la evolución del relato, la comprensión de que las distintas crónicas no

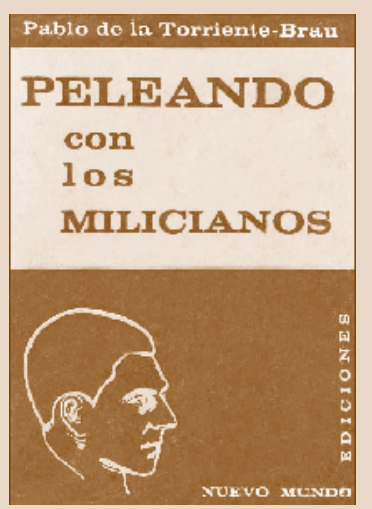
(1) 
iluminan aspectos dispares a la manera de fotografías estáticas, sino que se producen algunas transformaciones sobre una línea argumental de máxima coherencia. En primer lugar, hay un movimiento que tiene su punto de partida fuera de España (en París y Bruselas) y que, desde una perspectiva exterior, observa las manifestaciones de adhesión a la República en ambas ciudades; posteriormente, el periodista atraviesa la frontera y se enfrenta a la guerra ya en territorio español, en la retaguardia de Barcelona, lo que le surte de material para cinco crónicas; por último, un tercer estadio tiene lugar en Madrid, epicentro de la guerra en estos meses iniciales, donde el personaje da un paso más y llega hasta el frente de combate. El trayecto, con sus tres paradas marcadas (extranjero, retaguardia, frente) en cada uno de los lugares, es un viaje directo, sin rodeos pero también sin retorno.

De manera paralela, un segundo desplazamiento tiene que ver con la condición del narrador, que, como ya he anunciado, se transforma de periodista en combatiente. La metamorfosis no se produce de modo repentino, sino que consiste en una lenta pero taxativa transformación. En su primera visita al frente ("Cuatro camaradas del enemigo"), el yo narrativo cumple un discreto papel, es apenas una voz que relata y no se muestra, un periodista que recoge la historia para transmitirla: "Ya yo podía contar algo de los primeros camaradas del enemigo que he conocido" (p. 162).

La primera fase de la metamorfosis tiene lugar en la crónica "En el parapeto", donde el personaje de Torriente Brau adquiere todo el protagonismo y en la que destacan dos pasajes significativos. En la segunda parte de ese texto, después de la polémica con el enemigo, se relata la convivencia del periodista con los soldados; la integración con ellos es tal que parece un anuncio de la conversión por venir (la conversión que ya se está produciendo): "La guardia de las dos me despertó. Lloviznaba y todos tuvimos que recogernos en una chabola. Allí, unos sobre otros, dormimos" (p. 196). El segundo hecho significativo es el intercambio de las herramientas del periodista y el teniente. Para certificar la muerte en el parapeto de una miliciana abatida por el enemigo, "el teniente Ruiz tomó mi pluma y escribió" (p. 198); muy poco después, es el propio Pablo de la Torriente el que coge las armas para disparar hacia la trinchera opuesta: "Yo tomé el rifle que había dejado Lolita Máiquez" (p. 200). El narrador recurre al mismo verbo para indicar ambas acciones y al lector no se le escapa el simbolismo de la escena, en la que Torriente Brau ocupa (bien sea momentáneamente) el lugar de la miliciana muerta. El periodista es ya de facto un combatiente.

Los aspectos de interés de las crónicas de Pablo de la Torriente Brau no terminan aquí. El estilo del corresponsal es a menudo sobrio y conte- 
nido, próximo a la neutralidad del lenguaje periodístico; formalmente, no se llevan a cabo como norma general inesperadas audacias. No obstante, hay momentos en los que el lenguaje cobra conciencia de sí mismo y adquiere una mayor poeticidad. La descripción del silbido de las balas, por ejemplo, recurre a un par de elaboradas y eficaces imágenes: "Decir que pasan como un mosquito de acero es parecido pero no es exacto. Su silbido semeja al de un hilo de alambre vertiginosamente enrollado desde el infinito" (p. 200). El estilo es más elevado cuanto mayor es la emoción: el peligro, la admiración, el entusiasmo. A este respecto, resulta paradigmática la crónica "Cuatro muchachas en el frente", uno de los textos en los que la voz del corresponsal se encuentra más conmovida; la juventud y el valor de las jóvenes mujeres luchadoras conducen al escritor a una demostración de destreza lírica:

Maruja tiene dieciocho años. Es la mayor de todas, pero parece la menor. Es pequeña, casi rubia, de grandes ojos infantiles. Le mataron el novio y el hermano y cayó ametrallada en la sierra de Guadarrama. Morirá en la montaña vengando a sus muertos. Ella dice que es la única manera de recordarlos. Y no siente el temor de la muerte. La vio tan pronto y la ha visto tan pródiga, que para ella ha perdido el prestigio del misterio. Es una muchacha del frente. Más pequeña que su fusil. Morirá en la montaña vengando a sus muertos. $Y$, sin embargo, sobre la tierra, muerta, parecerá, tan frágil, tan bonita, una paloma que cayó (pp. 167-168).

En este caso, las repeticiones, la selección de un adjetivo como "pródiga" acompañando a la muerte o la imagen de la paloma caída son rasgos representativos de una diáfana voluntad de estilo. En otras ocasiones, el dolor de la guerra gana la partida e impera entonces una lengua transparente que no ha de atraer la atención sobre sí misma. En este sentido, y del mismo modo que Pablo Neruda entenderá en Madrid que la sangre de los niños es una imagen tan impactante que no puede menoscabarla una comparación, Pablo de la Torriente comprende cuando ve morir a una miliciana que "es ridículo comparar con nada a una muchacha muerta en la guerra" (p. 198). Las grandes tragedias imponen una contención lingüística, una suerte de duelo en el lenguaje.

En otro orden de cosas, recordemos que es necesario leer las crónicas de Pablo de la Torriente Brau como cápsulas donde viajan unas determinadas ideas; lejos de ser un mero divertimento narrativo -al menos lejos de serlo exclusivamente-, hay que entenderlas como la expresión de una ideología innegable y concreta (y esto supone inevitablemente la reiteración de 
ciertos tópicos de la propaganda). Buena parte del texto "Barcelona bajo el signo de la revolución" se ocupa en realidad de proclamar el compromiso republicano por la defensa de la cultura: la protección de los monumentos y obras de arte o la explicación a la quema de iglesias. La narración del encuentro con Francisco Galán y su tropa incide insistentemente en la organización y la disciplina que caracterizan el proyecto del Partido Comunista; algo parecido sucede en el perfil del Campesino, a quien, para equilibrar su espontaneidad, define no por casualidad como "un militante político, obediente a la rígida disciplina del Partido Comunista Español" (p. 224). Por supuesto, una crónica como "En el parapeto", donde Pablo de la Torriente profiere la ideología del bando republicano como un proyectil hacia la trinchera de enfrente, contiene algunas semillas políticas: la más destacada, la solidaridad internacional, y particularmente de los pueblos hispanoamericanos, con España, "la que fue nuestra madrastra y ahora será nuestra hermana mayor” (p. 192). Así, las crónicas desde España de Pablo de la Torriente están trufadas de ideas prorrepublicanas; en el marco del relato vivaz se insertan, sin esconderse, las convicciones políticas de su autor, favoreciendo en consecuencia el diálogo del texto a distintos niveles.

\section{LAS CARTAS: UN MONÓLOGO ARREBATADO}

Entre el 25 de septiembre y el 13 de diciembre de 1936, Pablo de la Torriente Brau escribe un total de catorce cartas desde España. Todas ellas -salvo una, la del 28 de noviembre, desde Alcalá de Henares- están firmadas en Madrid; todas ellas se publican por primera vez en el libro Peleando con los milicianos de 1938. Son, en muchos sentidos, tan interesantes como las crónicas, puesto que contienen igualmente episodios de la guerra pero al mismo tiempo están redactadas con la naturalidad y frescura propias de la escritura privada. La abolición de algunas barreras permite el acceso a zonas habitualmente vetadas.

Ninguna de las catorce epístolas lleva un destinario expreso. ¿A quién están dirigidas estas cartas, que hablan con frecuencia y familiaridad a un interlocutor afectivamente próximo? Víctor Casaus, a partir de las palabras de Raúl Roa, asume que el destinatario desconocido es Jaime Bofill, otro cubano exiliado con él en Nueva York (y que poco después viajaría a la Guerra Civil siguiendo los pasos de Torriente Brau) (2005, p. 37). Aunque no se conozca el derrotero detallado de su correspondencia, la fortuna de que esta se haya conservado permite al lector zambullirse en la interioridad 
del personaje en el momento culminante de su existencia, reconstruir la acelerada metamorfosis que termina por precipitarlo a la muerte.

Las cartas de Pablo de la Torriente son un testimonio diáfano de la fascinación y el vértigo, un documento que atestigua la pasión y la intensidad con los que vive su tiempo en España. Buscando siempre el contacto con el pueblo, se conmueve ante el espectáculo de las manifestaciones en la tarde crepuscular, cuando "se van agrupando las mujeres y los hombres, engrosando las filas, cantando sus canciones, y en la sombra ya de la noche, con los faroles cubiertos de azul oscuro, los manifestantes se van a disolver por los barrios, cuando los estandartes rojos son ya negros, como la sangre que se ha puesto vieja" (2005, p. 61). En las descripciones de las manifestaciones del pueblo, su pluma se estiliza y compone algunas escenas de gran emotividad; en repetidas veces, la figura gigante de Cuba se destaca tras las brumas de emoción: "Sobre este cielo limpio y fino, que parece el cutis de una muchacha azul, brilla una luna que casi parece la de la bahía de La Habana, donde la tanta luz no deja dormir a los tiburones" (p. 67).

Ante el deslumbramiento de España, el conjunto de las cartas de Pablo de la Torriente puede ser leído como la manifestación de una premura: es el relato de una vida acelerada, condensada en un breve espacio de tiempo. Es por este motivo que de manera constante el corresponsal lamenta en sus cartas que "las veinticuatro horas miserables que tiene el día" lo "violentan" (p. 56) y limitan incesantemente, que "debía prolongarse el tiempo, aunque fuera por un decreto revolucionario" (p. 39). El periodista vive frenéticamente, exasperado por la ansiedad de exprimir al máximo cada experiencia y tener tiempo para contarla: "Trabajo infatigablemente. No siento en lo absoluto el cansancio, pero me hace falta más tiempo. Por muy rápido que escriba, siempre necesito estar por la calle recogiendo impresiones" (p. 47). Más adelante, a medida que su implicación con la guerra lo va convirtiendo en combatiente, irá siendo cada vez más problemático escamotear horas para la escritura: "Es el tiempo material el que me falta porque en el frente, y más en estos momentos, es muy difícil distraer una hora para nada que no sea la preocupación de la guerra" (p. 84). La eléctrica vida de Pablo de la Torriente en España, tal y como queda reflejada en su correspondencia, está marcada por la urgencia.

A este respecto, resulta de gran interés observar cómo se comporta el binomio escritura-guerra en la experiencia de Pablo de la Torriente. Haciendo caso de sus palabras, se podría pensar que, en la lección vertiginosa de la guerra, no sería fácil hallar el momento y la serenidad para escribir; que, inmerso en la vorágine española, el periodista rezagaría su escritura. 
La realidad, pese a ello, es la contraria: en muy poco tiempo, Pablo de la Torriente genera un número nada desdeñable de páginas. La singularidad consiste en hacer partícipe a su lector de la dificultad del mismo proceso. A veces, dice, "quisiera no tener que escribir por ahora, porque escribir me lleva el tiempo que necesito para ver" (p. 39). Escribir o vivir; he ahí la disyuntiva apremiante para el corresponsal que no da abasto en España. En varias ocasiones, el periodista se muestra a sí mismo en el acto de escribir mientras caen las bombas en algún lugar muy cercano: “iSi oyeras cómo truena el cañoneo! Parece que están sacudiendo todas las alfombras de Madrid” (p. 82). La incidencia de la guerra, naturalmente, lleva al caos de la escritura: "Todo esto que te escribo es un poco desordenado. Pero así es la guerra" (p. 73).

El corresponsal mantiene intacta hasta su muerte su ilusión revolucionaria. Tal y como afirma Niall Binns, sirviéndose de los conceptos de André Malraux, "hay casi siempre en Torriente Brau una fusión de la ilusión lírica y la necesaria disciplina de un buen comunista para organizar el apocalipsis" (2004, p. 322). No obstante, a la par que la lectura de las cartas permite visualizar la conversión del periodista en soldado ${ }^{3}$, tiene lugar de manera simultánea una evolución sentimental del personaje: abrasado por el calor desmesurado de la guerra, Pablo de la Torriente sufre una progresiva insensibilización que lo preocupa en los momentos de lucidez. La primera reflexión que evidencia su alarma se produce en la carta del 4 de noviembre, donde se asusta ante el cálculo de bajas de una maniobra: "Pienso en el número de muertos que esto costará, y me asombro de que sólo me queda el asombro aritmético. La muerte pierde su prestigio en la guerra. Porque se hace una prostituta barata. De veras hay que morir por acabar con la guerra" (p. 82).

Tan sólo unos días después, observa el mismo efecto en Pepe Galán, que ante la muerte de su compañera prosigue su rutina cotidiana -sonrisas a los

\footnotetext{
${ }^{3}$ No es una conversión repentina, sino un proceso que tiene varias fases. En realidad, parece que la semilla está desde el comienzo, pues en su mencionada carta de Nueva York del 6 de agosto ya se hace eco del temor de su compañera sentimental, Teté Casuso, que "no tiene fe ninguna en que yo solamente 'vaya a ver"' (p. 16). En su carta del 21 de octubre, ya en Madrid pero todavía como simple periodista, anuncia su posible toma de las armas, aunque el tono burlón no permita todavía tomarlo demasiado en serio: "Y, naturalmente, que si de veras se acentúa el peligro, pelearé en nombre de todos ustedes. Sólo de pensarlo ya me imagino sobre un montón de fascistas despanzurrados. Y si quedo con vida, te aseguro que me apoderaré de la chilaba de algún moro" (p. 46). El día 17 de noviembre ya se ha producido la transformación: "Ayer, por casualidad, sentí otra de las emociones de la guerra. La de estar en Madrid como un miliciano más" (p. 95). Su última carta es ya indiscutiblemente la de un hombre absorbido por el torbellino de la guerra.
} 
chistes incluidas- y únicamente se limita a comentar: “ $¿ H a s$ visto qué mala suerte?"; disgustado, el periodista concluye: "La guerra es tan dura que quita el dolor" (p. 84). El clímax de este proceso se alcanza en la carta del 21 de noviembre (que muestra a Torriente Brau ya en sus funciones de comisario y que merece la pena citar por extenso):

¿Qué me falta ya por ver, palpar y sentir de la guerra? Bueno, sentir, no. No se siente nada en la guerra. Terminó con ella la sensibilidad humana. Anoche regresaba en el carro con Campesino y traía en la mano el diario de un desertor que acababa de ser ejecutado. Y bromeábamos, con absoluta naturalidad, del frío que estaría pasando su cadáver, bajo la noche inclemente, de un fino e interminable lloviznar helado. Con su diario en la mano cabeceé un poco en tanto llegamos a Madrid. Comenzaba en francés; luego seguía en español.

Mientras cenaba iba leyendo y en esto me lo pidió otro con la promesa de devolvérmelo. Probablemente se perderá. Sin embargo, yo era un hombre sensible y acaso lo vuelva a ser. La otra noche, mientras se resolvía un asunto, López, el ayudante de Pepe Galán, abrió el radio del coche en mitad de un campo silencioso, cerca del enemigo. Tocaba una de las sensitivas baladas de Chopin que tantas veces he oído en medio de públicos recogidos, casi angustiados de emoción.

Yo, mientras ponía más atención a los posibles ruidos cercanos, recordé con cierta pena el tiempo en que la música tenía para mí horizontes más diversos que el de los himnos de la revolución desacordemente entonados por las compañías en marcha, estrafalarias, soñolientas y animosas. Pero así es la guerra de inhumana e insensible. Por eso nadie podrá jamás pintarla bien. Cuando uno se pone a escribir es que, por un momento siquiera, le ha vuelto a uno su capacidad de emocionar el recuerdo. Y ya es falso todo (pp. 100-101).

Hay en estos párrafos una evidencia de cómo la guerra acaba con la sensibilidad del hombre: el periodista y Campesino bromean sobre alguien que acaba de ser ejecutado, el cubano se queda dormido leyendo las confesiones de un hombre muerto y, sobre todo, no es capaz de sentir emoción ante una música que en otro tiempo lo ha conmovido profundamente; el arte ha perdido la batalla frente a la música revolucionaria. La conclusión es clara: la guerra no puede ser escrita porque el escritor se enfrenta a la paradoja de humanizar lo inhumano mediante la escritura ${ }^{4}$.

\footnotetext{
${ }^{4}$ Por otra parte, la alusión al diario que comienza escribiéndose en francés y continúa en español merece un pequeño comentario. Con una extraordinaria economía, la frase ilumina varias ideas: el desertor ejecutado no es español, sino un voluntario extranjero, fenómeno arquetípico de la Guerra Civil Española; además, en poco tiempo el voluntario francés ha experimentado un
} 
La correspondencia de Pablo de la Torriente desde España se convierte en un monólogo arrebatado. A medida que transcurre el tiempo y el corresponsal no recibe respuesta del otro lado, percibe más claramente su soledad. No por ello deja de escribir, lo que permite suponer que el fin último de la redacción de cartas no es estrictamente dialógico, sino que más bien obedece a un impulso ineluctable: se escribe por la necesidad imperativa de contar, porque no es posible no hacerlo. El 21 de noviembre, Pablo de la Torriente Brau dirige el primer reproche hacia los responsables de El Machete, preguntándose si habrán publicado ya alguna de sus crónicas (p. 106). Después va a censurar a su tácito interlocutor, a quien despide en su carta del día 28 con una cariñosa amonestación: "Y por tu madre, viejo, escribe alguna vez, que me figuro que tú eres manco o cosa por el estilo" (p. 113). En su última carta, con fecha de 13 de diciembre, reitera el lamento: "No sé a qué atribuir esto. Quisiera tener una noticia concreta en algún sentido y no se me oculta que de una forma u otra, si tenían interés, bien han podido hacerme llegar noticias de ustedes" (p. 114). Cierra esa misma carta (¿el último texto que escribe Pablo de la Torriente Brau?) una despedida amarga: "Recuerdo a todos aunque ninguno se acuerde de mandar una línea" (p. 120). Mucho antes de que su destinatario pueda leer estas líneas al otro lado del Atlántico, su autor cae abatido en las cercanías de Majadahonda. Su cuerpo permanece algún tiempo en campo enemigo hasta que logra ser rescatado. Del mismo modo que Campesino y él han imaginado al desertor congelado, es fácil suponer que su propio cadáver sufre el implacable frío de diciembre 5 .

proceso de españolización hasta acabar redactando el diario - una escritura íntima, portavoz directo de los pensamientos- en español. La intensidad de la guerra produce rápidamente enormes transformaciones en las vidas humanas, y a la luz de estas reflexiones, es difícil no pensar en un paralelismo (evidente) entre el desertor ejecutado y el propio Pablo de la Torriente.

${ }^{5}$ El frío es un leitmotiv en la correspondencia de Pablo de la Torriente; de algún modo, parece un presagio de su infausto final. En su carta del 10 de octubre, pide a su corresponsal que le envíe un abrigo: "Bien, otro problema es el del puñetero frío. En Madrid dicen que no hace tanto como en Nueva York, pero ya ayer la sierra estaba nevada por las cumbres. Si te es posible consígueme por allá una capa-abrigo, bien chula. Porque no es justo que un corresponsal de mi categoría, representante de New Masses y El Machete, ande por las montañas con su sencillo lumber-jacket, temblando más que un condenado a muerte, a pesar de no tener miedo" (p. 42). En esa misma carta, en un tono de broma que a posteriori resulta profético, aventura que "el día menos pensado te llega la noticia de que el Corresponsal de Guerra ha muerto helado en la sierra” (p. 43). En su carta del 21 de noviembre repite la misma queja: "Y de frío nada te digo. Moriré no de bala sino de frío" (p. 106). La protesta llega hasta la última de sus cartas, donde recuerda cerca del final: "Hay un frío espantoso. Si me descuido muero de frío. Tengo un chaleco de piel de oveja y también me he conseguido una chilaba de moro, muy bonita. Pero nada me alcanza. Tengo los pies adoloridos. No sé cómo voy a poder aguantar este invierno sin calefacción” (p. 120). Lo cierto es que Torriente Brau no llegaría a saber de ese invierno tan temido. 


\section{EL HOMBRE DE GIGANTE ESQUELETO}

Después de tres trepidantes meses en España, la muerte prematura de Pablo de la Torriente Brau lo eleva a la categoría de símbolo y mártir de la intelectualidad de Cuba e Hispanoamérica. A partir de ese instante, no dejan de multiplicarse los gestos, los homenajes y los textos escritos en su memoria. Ensayar una nómina de todos ellos es sencillamente imposible en el breve espacio de este artículo.

La crónica de su entierro, escrita por Lino Novás Calvo, es seguramente el texto más conocido en torno a la figura de Pablo de la Torriente, además de uno de los más cautivadores testimonios del vínculo entre España e Hispanoamérica durante la guerra. Ampliamente difundida en la prensa del continente $^{6}$, no es difícil calibrar el impacto que debe de provocar en la isla -voraz consumidora de las noticias provenientes de España- la muerte del periodista y revolucionario, del compañero de letras de muchos intelectuales. Hay en la crónica una serie de imágenes memorables que ya proyectan la figura de Torriente Brau hacia un espacio de trascendencia: el velatorio solemne del cadáver por su parte y la del poeta Antonio Aparicio, el discurso de Campesino con la voz quebrada, la procesión fúnebre "por la noche adentro, hacia la gran noche donde deberíamos dejar al compañero querido". El descenso del cuerpo del amigo a la fosa es el clímax de emoción del relato:

Y llega la hora más triste y honda. Una larga fila de fosas abiertas iba desde los cipreses al muro. Hoyos abiertos en la tierra dura y seca, en la tierra pelada de Castilla, que esperaban a no importa qué cuerpo de trabajador o combatiente. Los soldados de la brigada encerraron una en su cerco de bayonetas. Los demás engrosaron el círculo y aguardamos, se hizo un completo silencio. Sólo se oían las respiraciones contenidas. A nuestra espalda, como gigantes de fantasía triste, nos velaban los árboles de la muerte. [...] Al discurso de despedida, siguió la Internacional cantada en coro. Los puños se proyectaban a la luna contra la tierra ocre por encima de las tumbas. Una descarga rasgó el himno, pero éste siguió sin interrupción, como un símbolo. [...] Unos cuantos compañeros rodearon el ataúd, y esperamos a que lo bajaran a la sepultura. En pocos segundos desapareció en la sombra. La luna parecía haberse fijado, más espesa, en los bordes arrancándole una luz fosforescente. Pablo había bajado a lo hondo de la tierra (Novás Calvo, 1937).

\footnotetext{
${ }^{6}$ Se publica acaso por primera vez en Repertorio Americano en enero de 1937, pero es reproducida por numerosos medios; entre ellos, la revista cubana Mediodía lo reimprime el 25 de febrero de 1937.
}

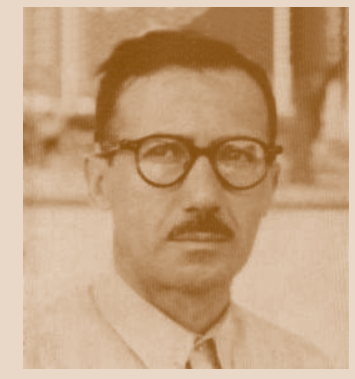

L. Novás 
Miguel Hernández -que aparece como personaje de la crónica- y Pablo de la Torriente traban, en el breve y eléctrico tiempo de la guerra, una fulgurante amistad. Cuando en julio de 1937, el poeta Nicolás Guillén, que también viaja como corresponsal a España, encuentra a Miguel Hernández en Valencia, mantienen una conversación (donde también está presente Langston Hughes) en la que el alicantino recuerda con mucha ternura a su amigo cubano: "Yo le quise mucho. Después de aquella noche que les digo, nos separamos durante varios meses. Nos volvimos a encontrar en Alcalá de Henares, a pesar de que habíamos estado juntos, sin saberlo, en los combates de Pozuelo y de Boadilla del Monte. ‘QQué haces?', me preguntó alegremente al abrazarnos. 'Tirar tiros', le contesté yo, riéndome también” (1937). Además de estas palabras, el testimonio literario que deja Miguel Hernández sobre Pablo de la Torriente es amplio. Después de la "Elegía primera" a García Lorca, la "Elegía segunda" de Viento del pueblo, impreso en 1937 en la editorial del Socorro Rojo, está dedicada a él (“'Me quedaré en España compañero' / me dijiste con gesto enamorado" (1989: 76). Frente al cadáver "reducido" que sorprende a Lino Novás Calvo, el agigantamiento de la figura del hombre que ya ha trascendido contribuye a la mitificación del personaje ${ }^{7}$.

Mientras tanto, hay en Cuba de manera paralela un multitudinario clamor en torno al héroe caído en España. Poemas como el "Canto elegiaco" de Ramón Guirao alimentan desde muy temprano -se publica en el costarricense Repertorio Americano en marzo de 1937- el fuego de su memoria. Unos días después, en abril, Emilio Ballagas publica en la revista Mediodía su poema -en un tono mucho más liviano- "A Pablo de la Torriente Brau". La lista es interminable 8 . Cabe destacar como curiosidad un breve apunte de Juan Ramón Jiménez; en su diario, el poeta onubense, aun no habiendo

\footnotetext{
${ }^{7}$ Junto a este poema, Miguel Hernández escribe durante la guerra una obra de teatro en verso titulada Pastor de la muerte, donde sobresale un personaje llamado El Cubano que no puede ser otro que Pablo de la Torriente. Amado del Pino y Tania Cordero, quienes han estudiado la relación de Miguel Hernández con los escritores cubanos, analizan algunos aspectos de la pieza dramática (Del Pino y Cordero 2013, p. 50). Dicho sea de paso, el propio Amado del Pino, dramaturgo cubano, ha fabulado con su obra Reino dividido (2011) sobre la amistad entre Pablo de la Torriente Brau y Miguel Hernández. Para ampliar información acerca de la relación entre ambos escritores, es posible consultar Casaus (2008, pp. 19-26).

${ }^{8}$ Únicamente con los poemas escritos a la memoria de Pablo de la Torriente Brau será posible armar varios volúmenes como El calor de tantas manos (2006), que, además de algunos poemas firmados por él, reúne una considerable suma de poemas de otros autores. Por otra parte, el corpus de textos en prosa -necrológicas, apuntes y recuerdos- es tan abundante o más que el de las creaciones poéticas, como puede comprobarse en la antología Pablo: 100 años después (Torriente Brau, 2001).
} 
conocido personalmente al cubano, elogia "la fe, la esperanza, la caridad, el noble heroísmo de otro hombre palpitantemente joven y poeta, que deja una hirviente paz y su patria viva para morir con el corazón en la mano, por el mundo que sueña, en otra. Esta vez, la otra patria ha sido España, el héroe, un cubano: Pablo de la Torriente. Yo, como español del mundo que él soñaba, me inclino ante el ejemplo jeneroso de su muerte" (1981, p. 101).

Así, la figura de Pablo de la Torriente Brau ha pervivido hasta nuestros días. Desde mediados del siglo XX, los intereses de la Revolución han hecho de él un símbolo acrisolado: la creación del Centro Cultural Pablo de la Torriente Brau y el sostenido esfuerzo para respaldar los trabajos de investigación en torno a su figura y su memoria son buena prueba de ello. No obstante, el interés del personaje, por todos los elementos que se examinan a lo largo de estas páginas, parece a todas luces justificado: tanto a nivel textual como biográfico, Pablo de la Torriente es una excelente medida del impacto de la Guerra Civil Española en Cuba y un punto de partida necesario en la historia de sus corresponsales hispanoamericanos.

\section{REFERENCIAS}

Bello, A. A. (2003). El mártir de Majadahonda. Pablo de la Torriente Brau y su época. La Habana: Ciencias Sociales.

Binns, N. (2004). La llamada de España. Barcelona: Montesinos.

Casado Fernández, A. (2014). "'Con el sol español puesto en la cara y el de Cuba en los huesos'. Pablo de la Torriente Brau en la Guerra Civil Española", en Carmen de Mora y Alfonso García Morales (eds.), Viajeros, diplomáticos y exiliados. Escritores hispanoamericanos en España (1914-1939), vol. III. Bruselas: Peter Lang.

Casaus, V. (2005). "Pablo de la Torriente Brau en la Guerra Civil Española", prólogo a Cartas y crónicas de España. La Habana: Ediciones la Memoria. Centro Cultural Pablo de la Torriente Brau. . (2007). Pablo: con el filo de la hoja. La Habana: Ediciones la Memoria. Centro Cultural Pablo de la Torriente Brau. . (2008). "Pablo y Miguel", en VVAA: Homenaje a Miguel Hernández. Actas de las I Jornadas Hernandianas en Cuba (pp. 19-26). Orihuela: Fundación Cultural Miguel Hernández.

Chacón y Calvo, J. M. (2009). Diario íntimo de la revolución española. Madrid: Verbum.

Del Pino, A. y Cordero, T. (2013). Los amigos cubanos de Miguel Hernández. La Habana: Ediciones la Memoria. Centro Cultural Pablo de la Torriente Brau.

Ferrer Díaz, J. (2011). “¡Que hable el cubano!”, prólogo a Peleando con los milicianos. Madrid. Verbum. 
Guillén, N. (1937). “Un poeta en espardeñas. Hablando con Miguel Hernández", Mediodía, La Habana, vol. II, n. 39, 25 de octubre, pp. 11-18.

Hernández, M. (1978). Teatro completo. Madrid: Ayuso. . (1989). Viento del pueblo. Madrid: Cátedra.

Jiménez, J. R. (1981). Juan Ramón Jiménez en Cuba. La Habana: Arte y Literatura.

Novás Calvo, L. (1937). "El entierro de Pablo de la Torriente Brau”, Repertorio Americano, San José de Costa Rica, 23 de enero.

Torriente Brau, P. de la (1938). Peleando con los milicianos. México: México Nuevo.

. (2001). Pablo: 100 años después. La Habana: Ediciones la Memoria. Centro Cultural Pablo de la Torriente Brau.

. (2005). Cartas y crónicas de España. La Habana: Ediciones la Memoria. Centro Cultural Pablo de la Torriente Brau.

Torriente Brau, Z. de la (2006). Papeles de familia. La Habana: Ediciones la Memoria. Centro Cultural Pablo de la Torriente Brau. 